\title{
Behavior analysis by model slope experiment of artificial rainfall
}

\author{
Min Cheol Park \\ Kumoh National Institute of Technology, Gumi-si, Republic of Korea \\ Correspondence to: Min Cheol Park (xlage0@naver.com) \\ Received: 14 April 2015 - Published in Nat. Hazards Earth Syst. Sci. Discuss.: 22 June 2015 \\ Revised: 5 February 2016 - Accepted: 22 February 2016 - Published: 18 March 2016
}

\begin{abstract}
In this study, we performed a model slope experiment with rainfall seepage, and the results were compared and verified with the unsaturated slope stability analysis method. In the model slope experiment, we measured the changes in water content and matric suction due to rainfall seepage, and determined the time at which the slope failure occurred and the shape of the failure. In addition, we compared and verified the changes in the factor of safety and the shape of the failure surface, which was calculated from the unsaturated slope stability analysis with the model experiment. From the results of experiment and analysis, it is concluded that the unsaturated slope stability analysis can be used to accurately analyze and predict rainfall-induced slope failure. It is also concluded that in seepage analysis, setting the initial conditions and boundary conditions is very important. If engineers will use the measured porewater pressure or matric suction, the accuracy of analysis can be enhanced. The real-time monitoring system of porewater pressure or matric suction can be used as a warning of rainfall-induced slope failure.
\end{abstract}

\section{Introduction}

Recently, there have been many natural disasters due to climate change. In particular, slope failure in downtown areas has caused loss of lives and of property. The causes of slope failures around the world are intense rainfall, rapid snowmelt, water level changes in rivers or lakes at the foot of slopes, volcanic eruptions, and earthquakes (Wieczorek, 1996). Among these, slope failure resulting from rainfall is the most frequent one in the case of Korea, where there are four seasons each year, and which is located within a midlatitude region not prone to earthquakes. Slope failure is frequently due to antecedent rainfall, a rainy spell effect in sum- mer, and freezing and thawing in the spring ( $\mathrm{Oh}$ and $\mathrm{Lu}$, 2015).

When evaluating slope stability, geology, hydraulics, hydrology, and soil mechanics are all taken into account. Geologically, the cause of slope failure takes into account the orientation of the joint plane, which is weak ground and is especially important in the rock slope. As regards to hydraulics and hydrology, the external forces that influence slope stability include the groundwater table and rainfall. In a slope stability analysis, the following are used: either (1) the method for determining and analyzing the groundwater table, or (2) the method for considering the seepage of rainfall.

When considering a groundwater table, we assume that it is located on the inclined plane of a slope, leading to a design that is very conservative and excessive. When considering the effects of rainfall, we take into account the geographical conditions, drainage conditions, and the regional rainfall intensity and duration determined by the design frequency, while performing seepage and slope stability analysis. The unsaturated slope design method can be analyzed more accurately or less conservatively than the traditional method (Oh and $\mathrm{Lu}, 2015)$.

In soil mechanics, the causes of a slope failure are porewater pressure and water content, which reduce the shear strength of a slope or increase the shear stress (Brand, 1981; Brenner et al., 1985). In a traditional slope stability analysis, cohesion and internal friction angle under saturation are applied to calculate the shear strength, and the strength parameters under unsaturation are applied when considering the rainfall seepage. However, there are limitations to the restricted geotechnical survey, inhomogeneity and anisotropy of the soil slope (Oh and Lu, 2015). Also, an intense rainfall differs from the conditions included in the design, and can occur due to an abnormal change in climate. Because of these limitations, slope failure can occur (Tohari et al., 2007). 
Table 1. Physical properties of soil.

\begin{tabular}{|c|c|c|c|c|}
\hline \multicolumn{2}{|c|}{$G_{\mathrm{S}}$} & \multirow{2}{*}{$\begin{array}{l}2.53 \\
18.95\end{array}$} & \multirow{2}{*}{$\frac{\mathrm{PL}(\%)}{D_{10}(\mathrm{~mm})}$} & \multirow{2}{*}{$\begin{array}{l}- \\
0.25\end{array}$} \\
\hline Compaction test & $\gamma_{\mathrm{d}, \max }\left(\mathrm{kN} \mathrm{m}^{-3}\right)$ & & & \\
\hline \multirow{3}{*}{ Sand replacement method } & $\mathrm{OMC}(\%)$ & 11.50 & $D_{30}(\mathrm{~mm})$ & 0.78 \\
\hline & Dry unit weight $\gamma_{\mathrm{d}}\left(\mathrm{kN} \mathrm{m}^{-3}\right)$ & 16.05 & $D_{60}(\mathrm{~mm})$ & 1.87 \\
\hline & $\mathrm{w}(\%)$ & 8.42 & Gravel (\%) & 6.05 \\
\hline \multicolumn{2}{|c|}{$k_{\mathrm{S}}\left(\mathrm{m} \mathrm{s}^{-1}\right)$} & $1.30 \times 10^{-4}$ & Coarse sand (\%) & 78.80 \\
\hline \multirow{2}{*}{ Triaxial compression test } & Cohesion $(\mathrm{kPa})$ & 0.0 & Fine sand $(\%)$ & 13.20 \\
\hline & Internal friction $\left({ }^{\circ}\right)$ & 33.6 & Silty $(\%)$ & 2.00 \\
\hline \multicolumn{2}{|c|}{ Uniformity coefficient $C_{\mathrm{u}}$} & 7.47 & USCS & SW \\
\hline \multicolumn{2}{|c|}{ Coefficient of curvature $C_{\mathrm{c}}$} & 1.32 & - & \\
\hline
\end{tabular}

In general, rainfall-induced slope failures are caused by increased pore pressure and seepage force during periods of intense rainfall (Anderson and Sitar, 1995; Sidle and Swanston, 1982; Wang and Sassa, 2003; Sitar et al., 1993). Previous studies have been conducted to understand the failure mechanism of a slope, and to determine the point of initiation of failure. Until now, the process of slope failure is not clear (Regmi et al., 2014; Tohari et al., 2007).

Recently, field measurements and laboratory experiments on model slopes have been conducted in order to understand the process of slope failure and seepage under rainfall. The studies of field measurements used porewater pressure because it is easy to measure and it is the most important factor in the process of the slope (Johnson and Sitar, 1990; Rahardjo et al., 2005). However, it is difficult to generalize about the process of rainfall-induced slope failure because the mechanism and behavior of porewater pressure depends in each case on the hydrology, topography, and soil properties of the slope (Sitar et al., 1993).

Laboratory experiments were conducted in order to understand the process of slope failure, and to monitor porewater pressure, soil suction, groundwater depth and slope deformation, and the failure surface within a slope (Fukuzono, 1987; Kitamura et al., 1999; Regmi et al., 2014; Sasahara, 2001; Tohari et al., 2007; Yagi and Yatabe, 1987; Yokota et al., 2000).

Slope stability is calculated by using the ratio of shear strength and shear stress that occurs along the failure surface. In traditional slope stability analysis, the saturated strength parameters are applied by assuming the worst case, and the groundwater table is located on the inclined plane of a slope during the wet season. However, when rainfall seepage is considered, then since the weight of the soil increases due to the seepage of water, the shear stress is increased and the matric suction is decreased, which leads to a decrease in shear strength. As a result, the factor of safety, defined as the ratio of shear stress and shear strength along the failure surface, dramatically decreases. Especially when it happens around the failure surface, the soil around the failure surface loses its shear strength, leading to a collapse.

In this study, we performed a model slope experiment to understand the process of water seepage and slope failure caused by rainfall; and we compared and verified the results with unsaturated slope stability analysis. In the model slope experiment, we created artificial rainfall on a slope and measured the changes in water content, which acts as a load factor during seepage, and the change of matric suction, which acts as a resistance factor. Also, we identified the time and the shape of slope failure after the rainfall seepage.

Unsaturated slope stability analysis was used to calculate the change in the factor of safety due to rainfall seepage, by performing seepage analysis and the limit equilibrium method. Seepage analysis was performed under an unsteady state due to rainfall, and the factor of safety was calculated from the calculated head value. We compared and verified the changes in the factor of safety, as well as the time and shape of the slope failure resulting from the rainfall, with the results from the model experiment.

\section{Material and methods}

\subsection{Model slope experiment}

The experiment devices consisted of a soil container $(2.0 \mathrm{~m} \times 1.0 \mathrm{~m} \times 0.6 \mathrm{~m})$, an artificial rainfall simulator, and a measuring device. A $5 \mathrm{~cm}$ drainage layer was formed with crushed stones in the bottom layer of a slope. This was done in order to ensure that slope failure occurred only when there was a change in the shear strength of the slope due to rainfall seepage.

In the slope model experiment by Tami et al. (2004), seepage flow changed due to the soil layer with a relatively small permeability, located at the bottom of a slope. In the experiments of Tohari et al. (2007) and Regmi et al. (2014), the 

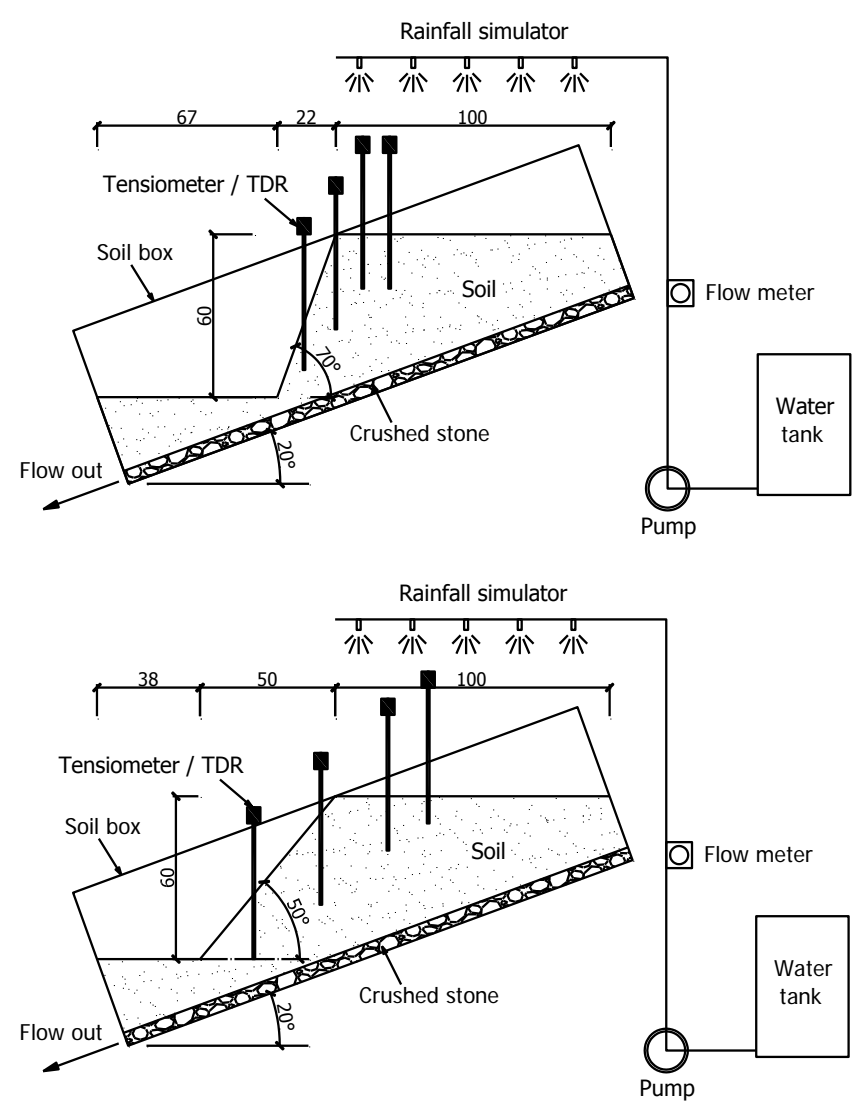

Figure 1. Experimental setup in Kumoh National Institute of Technology, Korea: (a) model slope of $70^{\circ}$ inclination, (b) model slope of $50^{\circ}$ inclination.

elevated groundwater table caused the failure surface to form at the toe of a slope.

In this study, we eliminated these influences and considered only a slope failure occurring due to rainfall seepage. In the soil container, a finite slope with a height of $60 \mathrm{~cm}$ and inclination of $70^{\circ}$ was formed. The slope was constructed uniformly, using plywood and tamper, with the degree of compaction being $85 \%$ and the height $20 \mathrm{~cm}$. It was formed in three layers (Fig. 1a). Prior to the model slope experiment of $70^{\circ}$ inclination, the preceding experiment was performed in $50^{\circ}$ inclination (Fig. 1b). This was conducted to verify the seepage behavior by rainfall seepages on the model slope, and its failure did not occur, but slope failure in the model slope of $70^{\circ}$ inclination did occur.

Table 1 shows the physical properties of soil for this experiments. We used weathered granite soil, which is the soil most prevalent in the mountainous terrain of Korea. According to the unified soil classification system, it is designated as SW (well-graded sand), with a specific gravity of 2.53 , an effective grain size of $0.25 \mathrm{~mm}$, and a coefficient of uniformity of 7.47. In the compaction test, the maximum dry unit weight and the optimal water content were calculated to be $18.95 \mathrm{kN} \mathrm{m}^{-3}$ and $11.50 \%$, respectively. In the direct shear test carried out under the same conditions as for the model slope, cohesion was $0 \mathrm{kPa}$ and the internal friction angle was $33.6^{\circ}$. The saturated coefficient of permeability of the constant-head method was calculated to be $0.00013 \mathrm{~m} \mathrm{~s}^{-1}$.

To determine the creation process of a rainfall-induced slope failure, we measured the water content, which acts as a load factor during seepage, and the matric suction, which acts as a resistance factor.

Water content was measured using a TDR (time-domain reflectometer) sensor. The TDR sensor uses the association between the dielectric constant and water content (Topp et al., 1980). Electrical pulses from the TDR-measuring device go through a probe and are then changed by water content. After a simple correction process, we found the value for the water content. The probe for the TDR sensor was the EC-5 from Decagon Devices Inc., and its dimensions are $8.9 \mathrm{~cm} \times 1.8 \mathrm{~cm} \times 1.7 \mathrm{~cm}$ (Bogena et al., 2007; Decagon devices, 2006). We performed the correction process with weathered granite soil, with the degree of accuracy being $\pm 3 \%$ and the resolution $0.1 \%$. The data logger used was an Em50 from Decagon Devices, measuring every $5 \mathrm{~min}$.

We measured matric suction using a tensiometer, which consists of a porous ceramic pipe and a transducer. The porous ceramic pipe was a Jet Fill tensiometer from Soilmoisture, and the pressure sensor was a tensiometer transducer from ICT International Pty Ltd. (Indrawan et al., 2012). In the Jet Fill tensiometer, porewater pressure is created from the surface tension of water at the contact point between a porous ceramic cup and the soil, and it is measured by the pressure sensor. The measuring range of the pressure sensor is $0 \sim-100 \mathrm{kPa}$, with a resolution of $0.1 \mathrm{kPa}$ and a degree of accuracy of $\pm 1.0^{\circ}$. The data logger used was LogoSens from OTT Hydrometry, and the measurements were taken every 5 min.

In the model slope of $70^{\circ}$ inclination, the water content and matric suction sensors were installed in four locations (Fig. 2a). Sensor A was placed $10 \mathrm{~cm}$ above the slope toe and $50 \mathrm{~cm}$ from the top of the slope, where the rainfall seepage occurs. Sensor B was placed $35 \mathrm{~cm}$ from the top of the slope, and sensors $C$ and $D$ were placed $20 \mathrm{~cm}$ from the top of the slope. In the model slope of $50^{\circ}$ inclination, the water content and matric suction sensors were installed in four locations (Fig. 2b). Sensor A was placed $60 \mathrm{~cm}$ from the top of the slope. Sensor B was placed $40 \mathrm{~cm}$ from the top of the slope, and sensors $\mathrm{C}$ and $\mathrm{D}$ were placed 20 and $10 \mathrm{~cm}$ from the top of the slope.

A rainfall simulator was set approximately $50 \mathrm{~cm}$ above the surface of the model slope. The rainfall simulator was controlled to provide artificial rainfall on the upper surface $(1.0 \times 1.0 \mathrm{~m})$ of the model slope. An intensity of artificial rainfall of $30 \mathrm{~mm} \mathrm{~h}^{-1}$ is the criterion of heavy rainfall in Korea. Also, saturated permeability was considered. The ponding of slope surface would have happened because the rainfall intensity was bigger than $30 \mathrm{~mm} \mathrm{~h}^{-1}$. The artificial rainfall would introduce surface erosion and the formation of gul- 
Table 2. Geotechnical and hydraulic properties of model slope.

\begin{tabular}{l|lc|lll}
\hline Analysis & \multicolumn{2}{|c|}{ Seepage } & \multicolumn{3}{c}{ Slope } \\
\hline Parameter & Soil & Crushed stone & Parameter & Soil & Crushed stone \\
\hline$u_{b}(\mathrm{kPa})$ & 0.452 & - & $\gamma_{t}\left(\mathrm{kN} \mathrm{m}^{-3}\right)$ & 16.05 & 19.00 \\
$n$ & 1.189 & - & $c^{\prime}(\mathrm{kPa})$ & 0 & 0 \\
$\theta_{\mathrm{S}}(\%)$ & 0.38 & - & $\varnothing^{\prime}\left({ }^{\circ}\right)$ & 33.6 & 45.0 \\
$\theta_{\mathrm{r}}(\%)$ & 0.09 & & & & \\
$k_{\mathrm{S}}(\mathrm{m} / \mathrm{s})$ & $1.30 \times 10^{-4}$ & 0.13 & & - & \\
\hline
\end{tabular}
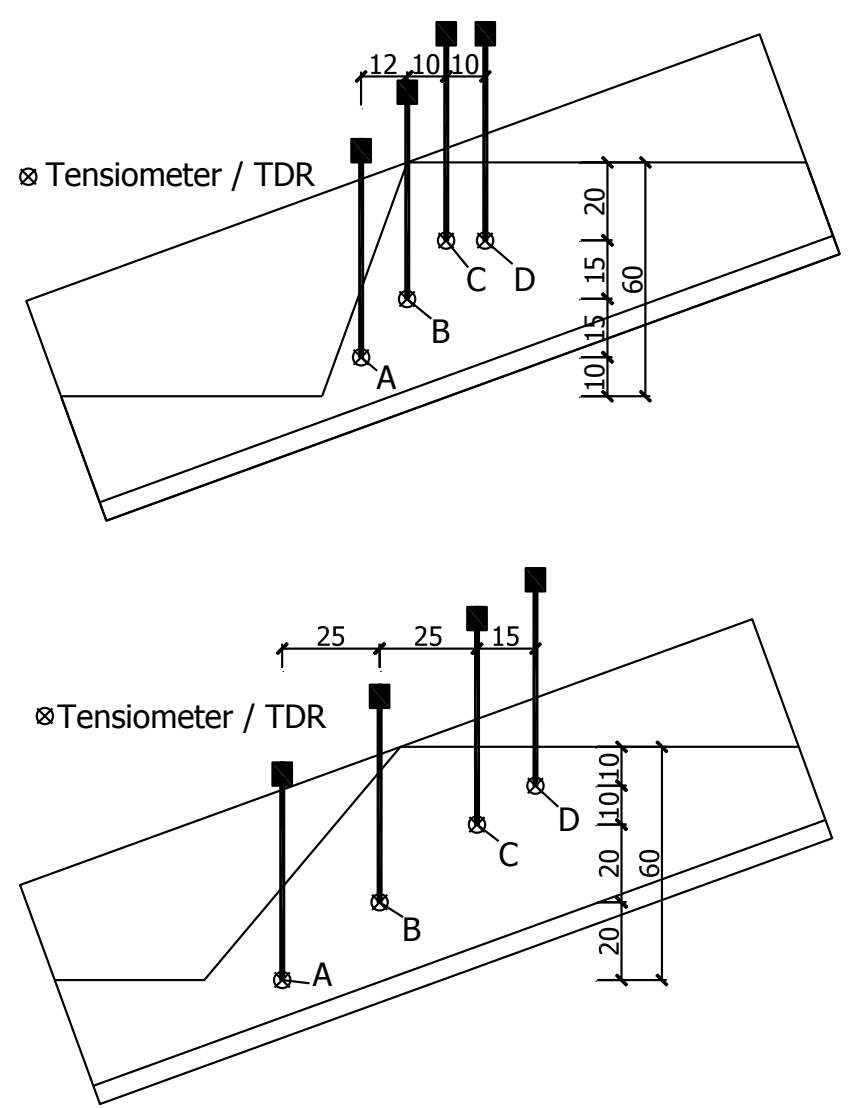

Figure 2. Model slope with arrangement of the TDR and tensiometer: (a) model slope of $70^{\circ}$ inclination, (b) model slope of $50^{\circ}$ inclination.

lies. The amount of water flowing into the sprayer arms was carefully controlled, and monitored through a flow meter.

\subsection{Numerical analysis}

Unsaturated slope stability analysis was carried out with seepage analysis and slope stability analysis. Seepage analysis under the unsteady conditions was performed first, and the factor of safety was calculated with the limit equilibrium method, by applying the water head value inside the slope to the slope stability analysis.
For slope stability analysis under transient unsaturated seepage conditions using the hydromechanical framework, only three additional parameters are needed. These are the residual water content $\theta_{\mathrm{r}}$, the air entry pressure $u_{b}$, and the pore size distribution parameter $n$. The soil water retention curves (SWRCs) were obtained from the pressure plate tests and fit to the Van Genuchten model using the RETC (RETention Curve) code (Van Genuchten, 1980). The Van Genuchten model was selected from among various SWRC models, because it is usually applied to analyze the weathered granite soil of Korea, and it has been verified by several researchers (Oh, 2015). Direct shear tests were conducted under saturated conditions in order to obtain shear strength parameters for the soil. As shown in Fig. 3 and Table 2, the air entry pressures $u_{b}$ are $0.452 \mathrm{kPa}$, the pore size distribution parameter $n$ is 1.189 , the residual water content $\theta_{\mathrm{r}}$ is 0.09 , and the saturated volumetric water content $\theta_{\mathrm{s}}$ is 0.38 .

The hydrological behavior due to infiltration of the artificial rainfall was analyzed numerically using the SEEP/W module of Geostudio 2007 (Krahn, 2007). The geometry of the model slope for numerical analysis was as in Fig. 4. Meshing was done with the combination of quadrangles and triangles, with the element size around $3 \mathrm{~cm}$.

In seepage analysis, setting the initial conditions and boundary conditions is very important. To analyze the unsteady state, we input the matric suction that was measured from the experimental process using the spatial function. The boundary condition of $30 \mathrm{~mm} \mathrm{~h}^{-1}$ of rainfall was applied only to the top of the slope, which was the same as in the model experiment. The inclination plane of the slope was set such that the seepage water could flow out. On the left, right, and bottom sides, an impervious boundary was placed, and the face of the layer of crushed stones was also set such that the seepage water could flow out. The results of the seepage analysis show unsteady states, so they are shown as the total stress, porewater pressure, and the water content with changes in time; and they were applied to the slope stability analysis.

\subsection{Slope stability analysis}

In the slope stability analysis, the limit equilibrium method was used, which the design standards have presented. It was 

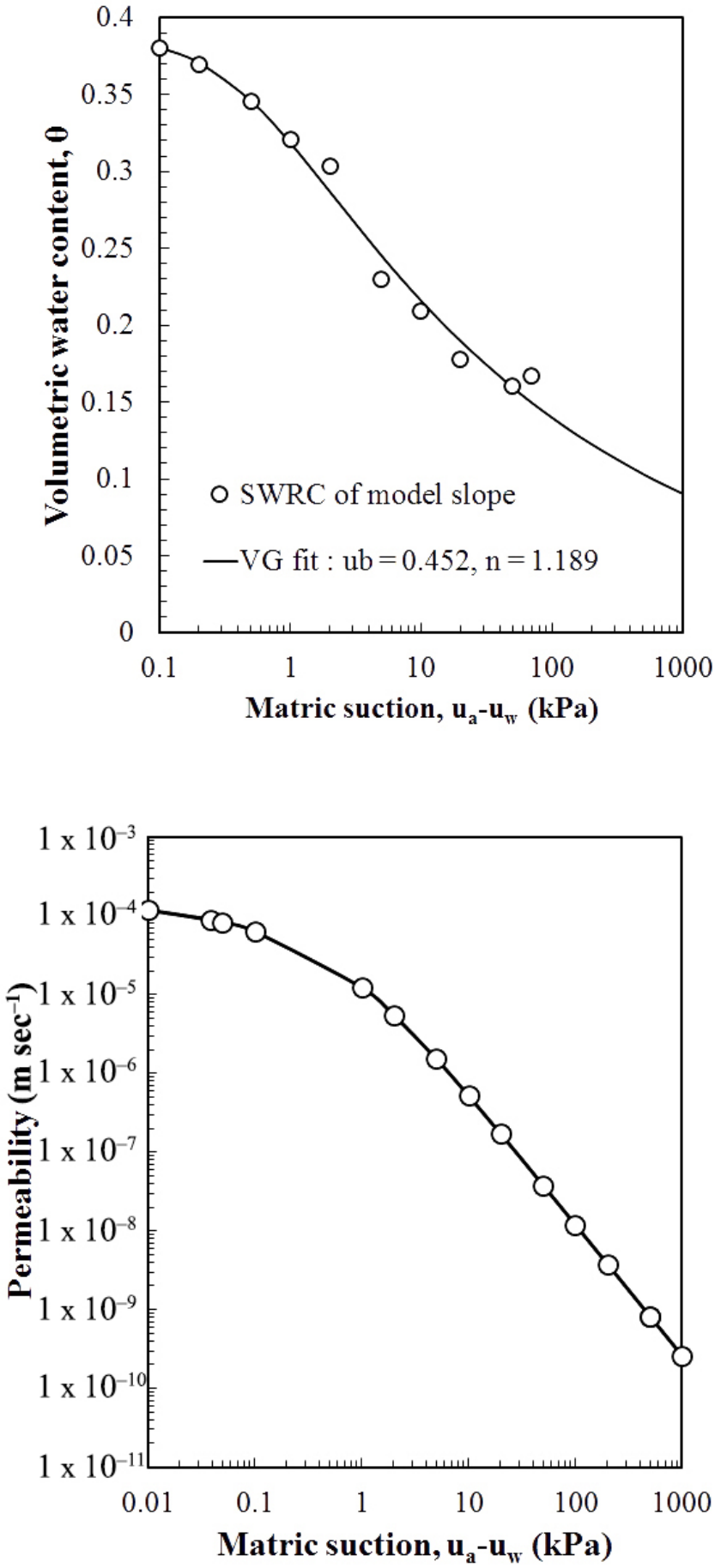

Figure 3. Hydromechanical properties of (a) soil water retention data, (b) hydraulic conductivity function.

determined by the ratio of shear stress and shear strength along the failure surface. The factor of safety was calculated using Eq. (1):

$\mathrm{FOS}=\frac{\sum_{i}\left(\tau_{f} l_{\text {base }}\right)_{i}}{\sum_{i}\left(\tau l_{\text {base }}\right)_{i}}=\frac{\sum_{i}\left[\left(c^{\prime}+\sigma^{\prime} \tan \varnothing^{\prime}\right) l_{\text {base }}\right]_{i}}{\sum_{i}\left(\tau l_{\text {base }}\right)_{i}}$,
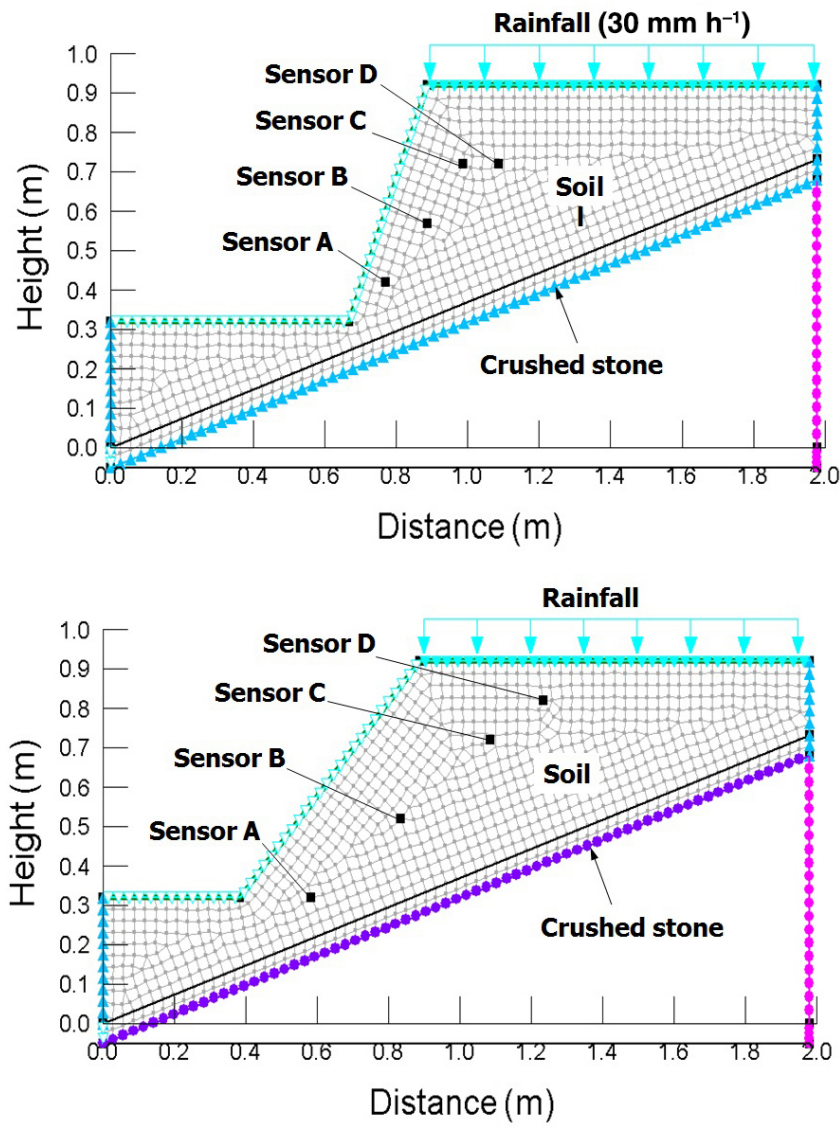

Figure 4. Geometry and boundary conditions of model slope: (a) model slope of $70^{\circ}$ inclination, (b) model slope of $50^{\circ}$ inclination.

where $i$ is the slice index and $l_{\text {base }}$ is the base length of each slice, $\tau_{f}$ and $\tau$ are the shear strength and shear stress, respectively, $c^{\prime}$ is the drained cohesion, and $\varnothing^{\prime}$ is the drained friction angle.

The factor of safety was calculated numerically using the SLOPE/W module of Geostudio 2007 (Geo-slope, 2007). The suction stress and the effective stress are incorporated into the shear strength in the SLOPE/W module as follows:

$$
\begin{aligned}
& \tau_{f}=c^{\prime}+\sigma^{\prime} \tan \varnothing^{\prime} \\
& =c^{\prime}+\left\{\left(\sigma-u_{\mathrm{a}}\right)+\frac{\theta-\theta_{\mathrm{r}}}{\theta_{\mathrm{s}}-\theta_{\mathrm{r}}}\left(u_{\mathrm{a}}-u_{\mathrm{w}}\right)\right\} \tan \varnothing^{\prime},
\end{aligned}
$$

where $u_{\mathrm{a}}$ is the pore air pressure and $u_{\mathrm{w}}$ is the porewater pressure, $\sigma^{\prime}$ and $\sigma$ are the effective stress and normal stress, $\left(u_{\mathrm{a}}-u_{\mathrm{w}}\right)$ is the matric suction, and $\theta_{\mathrm{r}}$ and $\theta_{\mathrm{s}}$ are the volumetric water contents at the residual and saturated states. 
Table 3. Variation of volumetric water content in the model slope of $50^{\circ}$ inclination.

\begin{tabular}{lllll}
\hline \multirow{2}{*}{ Sensor } & \multicolumn{4}{c}{ Volumetric water content $(\%)$} \\
\cline { 2 - 5 } & Initial & Wetting & Drying & Variation \\
\hline A & 17.69 & 32.31 & 21.60 & 10.71 \\
B & 17.01 & 21.51 & 19.56 & 1.95 \\
C & 11.91 & 19.64 & 14.63 & 5.01 \\
D & 15.05 & 30.61 & 18.20 & 12.41 \\
\hline
\end{tabular}

Table 4. Variation of matrix suction in the model slope of $50^{\circ}$ inclination.

\begin{tabular}{lllll}
\hline \multirow{2}{*}{ Sensor } & \multicolumn{4}{c}{ Matric suction $(\mathrm{kPa})$} \\
\cline { 2 - 5 } & Initial & Wetting & Drying & Variation \\
\hline A & 7.11 & 5.79 & 4.41 & 1.38 \\
B & 9.02 & 7.31 & 5.65 & 1.66 \\
C & 9.89 & 7.08 & 5.64 & 1.44 \\
D & 11.46 & 6.87 & 3.74 & 3.13 \\
\hline
\end{tabular}

\section{Results and discussion}

\subsection{Model slope of $50^{\circ}$ inclination}

Figure 5 and Tables 3 and 4 show the water content and the variation of matric suctions by rainfall seepage drainages in the model slope of $50^{\circ}$ inclination. The distribution of water contents was high in both of the top and bottom slopes for initial and seepage drainage but was low at the middle slope. High variations of water contents were exhibited at the top and bottom slopes. The distribution of matric suctions was initially high at the top slope but decreased towards the bottom slope. It was largely reduced at the top and bottom slopes due to the seepage of artificial rainfall and was shown to be low at the bottom similar to the distribution of initial matric suction. Unlike the variation of water contents, the variations of matric suctions were high only at the top. The distribution and variation of water contents and matric suctions were a little different at the bottom slope and this could be considered by the effect of the bottom drainage layer.

For initial water contents and matric suctions, the wetting procedure by rainfall seepages occurred rapidly so it increased the water content but reduced the matric suction. On the other hand, the drainage procedure of rainfall progressed more slowly than the wetting procedure. Sensor D, which is close to the surface, immediately responded to the variation of volumetric water contents due to seepage drainage of rainfall, and a sensor which is further away from the surface generated a relatively slow change because it needs time for seepage. For matric suctions, the top sensors demonstrated large and immediate responses to rainfall, similar to the behavior of top volumetric water contents, but the bottom sen-
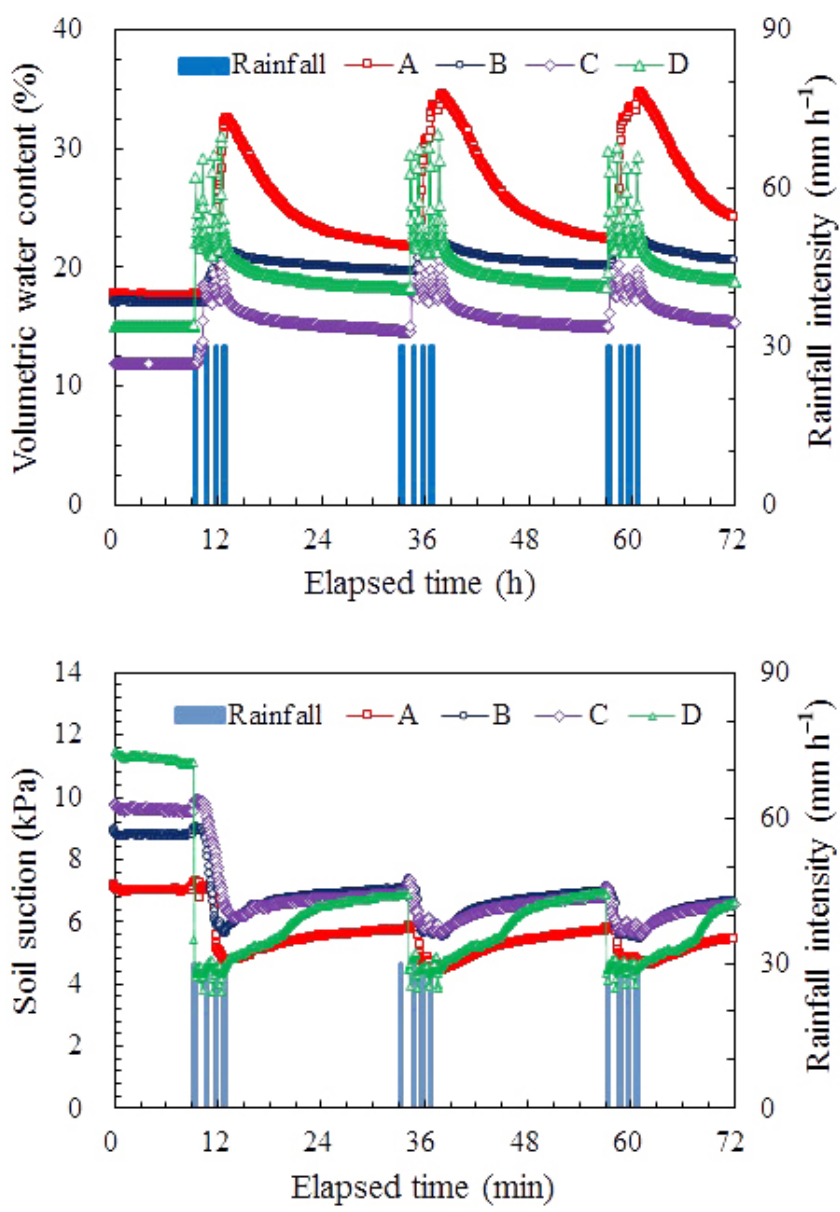

Figure 5. Variation of volumetric water content and soil suction in the model slope of $50^{\circ}$ inclination: (a) volumetric water content, (b) soil suction.

sors indicate small and slow responses. The reaction of bottom volumetric water contents was slow but indicated a large change. It means that there was a reduction of partial matric suctions at the bottom of the model slope where sensor A was situated in the bottom drainage layer.

Figure 6 shows a comparison of experimental data and the results of numerical analysis in volumetric water content in the model slope of $50^{\circ}$ inclination. In Fig. 6, the circles denote the experimental results; the rectangles denote the results of numerical analysis. Rainfall refers to the rainfall time and rainfall intensity; also failure refers to the time of slope failure. The behaviors by seepage drainage of rainfall did not occur in the area of sensors A and B which were installed at the bottom. Numerical analysis showed that the behaviors by seepage drainage of rainfall occurred around $\mathrm{C}$ and $\mathrm{D}$ sensors installed at the top slope of the model. However, the behavior of water contents in experimental results occurred overall at 4-6\% lower range than numerical analysis results.

Figure 7 compares the experimental data and the results of numerical analysis in soil suction in the model slope of 
Table 5. Variation of volumetric water content in the model slope of $70^{\circ}$ inclination.

\begin{tabular}{llllll}
\hline Parameter & $\mathrm{A}$ & $\mathrm{B}$ & $\mathrm{C}$ & $\mathrm{D}$ \\
\hline Initial water content (\%) & 4.60 & 3.75 & 6.89 & 5.79 \\
\hline Time until seepage (min) & 120 & 80 & 45 & 65 \\
\hline \multirow{3}{*}{ Failure after seepage } & $\mathrm{Time}(\mathrm{min})$ & 20 & 60 & 95 & 75 \\
\cline { 2 - 6 } & $\mathrm{VWC}_{\max }(\%)$ & 27.63 & 28.06 & 36.99 & 34.78 \\
\cline { 2 - 6 } & $\mathrm{VWC}_{\text {var }}(\%)$ & 23.03 & 24.31 & 30.10 & 28.99 \\
\hline $\begin{array}{l}\text { VWC }_{\text {max }} \text { is the maximum value of volumetric water content and } \\
\text { volumetric water content. }\end{array}$
\end{tabular}

Table 6. Variation of matrix suction in the model slope of $70^{\circ}$ inclination.

\begin{tabular}{|c|c|c|c|c|c|}
\hline \multicolumn{2}{|c|}{ Parameter } & A & $\mathrm{B}$ & $\mathrm{C}$ & $\mathrm{D}$ \\
\hline \multicolumn{2}{|c|}{ Initial matric suction $(\mathrm{kPa})$} & 30.35 & 36.04 & 31.38 & 30.77 \\
\hline \multicolumn{2}{|c|}{ Time until seepage (min) } & 100 & - & 45 & 45 \\
\hline \multirow{3}{*}{ Failure after seepage } & Time (min) & 40 & - & 95 & 95 \\
\hline & $\left(u_{\mathrm{a}}-u_{b}\right)_{\min }(\mathrm{kPa})$ & 4.87 & 4.86 & 6.19 & 5.93 \\
\hline & $\left(u_{\mathrm{a}}-u_{b}\right)_{\mathrm{var}}(\mathrm{kPa})$ & 25.48 & 31.18 & 25.19 & 24.84 \\
\hline
\end{tabular}

$50^{\circ}$ inclination. In Fig. 7, the circles in legend denote the experimental results; the squares denote the results of numerical analysis. Rainfall refers to the rainfall time and rainfall intensity; also failure refers to the time of slope failure. From the results of numerical analysis, it is evident that the behaviors by seepage drainage of rainfall did not occur in sensor A, which was installed $60 \mathrm{~cm}$ from the top of slope. A slight variation of matric suction occurred in sensor B. A clear variation of matric suctions occurred in sensors $C$ and D, installed $20 \mathrm{~cm}$ and $10 \mathrm{~cm}$ from the top of slope, but matric suctions were shown in the numerical analysis to have occurred overall at $4 \mathrm{kPa}$ lower range than in experimental results.

From the results of numerical analysis and the model slope experiment, it is evident that an increase of water contents and a decrease of matric suctions due to rainfall seepage occurred rapidly, but a decrease of water contents and an increase of matric suctions due to drainage occurred gradually. This evidences a hysteresis of seepage drainage procedures in unsaturated soils. Even with similar behaviors in the model slope experiment and the numerical analysis, the difference could be considered by applying the SWRCs obtained from disturbed specimens in the numerical analysis.

\subsection{Model slope of $70^{\circ}$ inclination}

Figure 8 and Tables 5 and 6 show the variation of volumetric water content and soil suction in the model slope of $70^{\circ}$ inclination. Table 5 show the measured water content due to artificial rainfall seepage. Simulated artificial rainfall of
$30 \mathrm{~mm} \mathrm{~h}^{-1}$ began $180 \mathrm{~min}$ after the water content was measured. After $320 \mathrm{~min}$, model slope failure occurred. Depending on the depth of TDR sensor installation, there were differences in the time that the movement started.

For sensor A, which was installed $50 \mathrm{~cm}$ from the top of the slope (10 cm above the slope toe), volumetric water content rapidly increased $120 \mathrm{~min}$ after the rainfall simulation began. Slope failure occurred $20 \mathrm{~min}$ after the volumetric water content increased in sensor A. For sensors B through D, which were placed 20 to $35 \mathrm{~cm}$ from the top, volumetric water content increased almost vertically 50 to $80 \mathrm{~min}$ after the rainfall simulation began, and the increase slowed down 20 to $30 \mathrm{~min}$ after that. At slope failure, sensors $\mathrm{C}$ and $\mathrm{D}$, which were placed $20 \mathrm{~cm}$ from the top, were close to the saturated water content of $38 \%$. The other sensors showed unsaturated water content. Therefore, we know that the slope failure happened before the area around the failure surface was completely saturated.

According to the experimental cases of Regmi et al. (2014) and Tohari et al. (2007), when the groundwater table existed on the toe of the slope, slope failure occurred at saturation; but when the groundwater table did not have an effect, slope failure occurred around the toe area of the slope before saturation.

Table 6 shows the measured matric suction according to rainfall seepage. The simulated rainfall of $30 \mathrm{~mm} \mathrm{~h}^{-1}$ began $180 \mathrm{~min}$ after measuring the model slope, and the slope failure occurred after $320 \mathrm{~min}$. For sensor A, which was installed $50 \mathrm{~cm}$ from the top of the slope $(10 \mathrm{~cm}$ above the slope toe), 

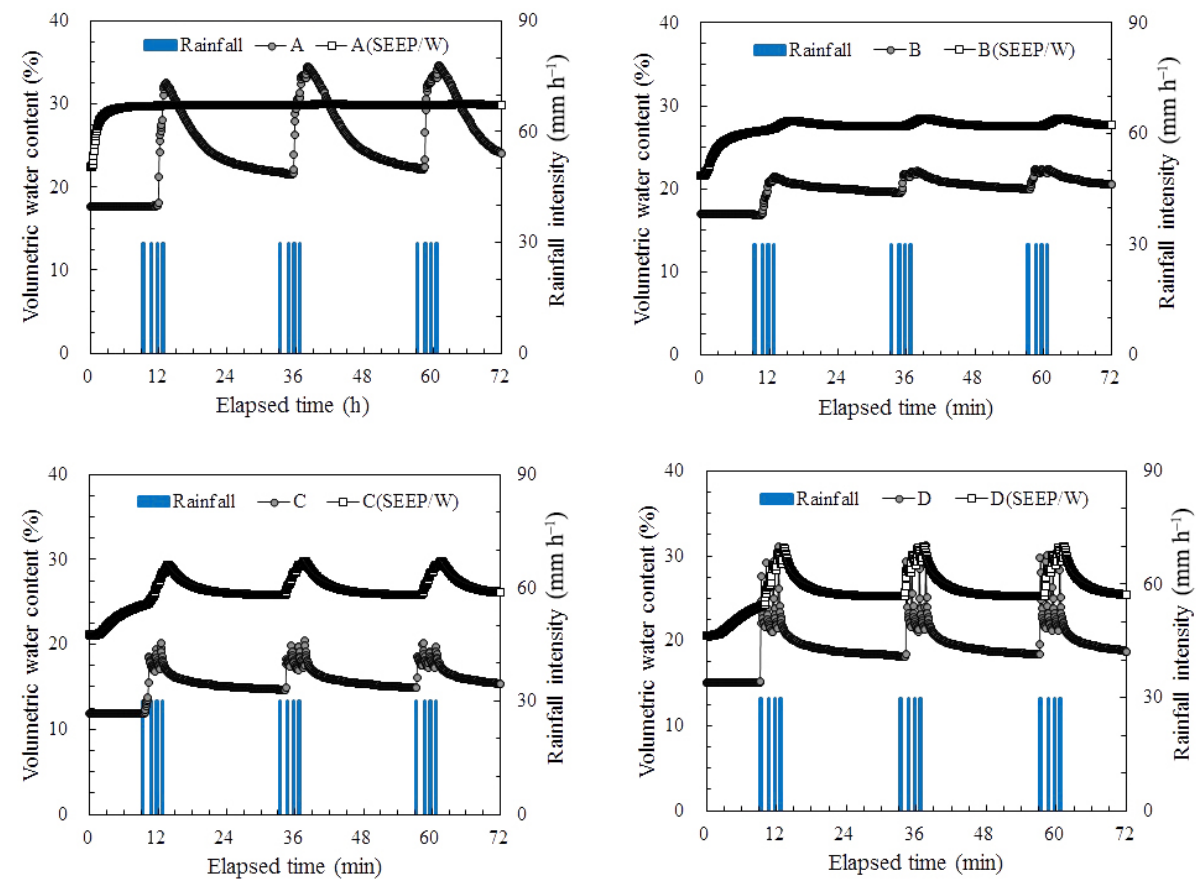

Figure 6. Comparison of volumetric water content of experimental data and results of numerical analysis in the model slope of $50^{\circ}$ inclination.
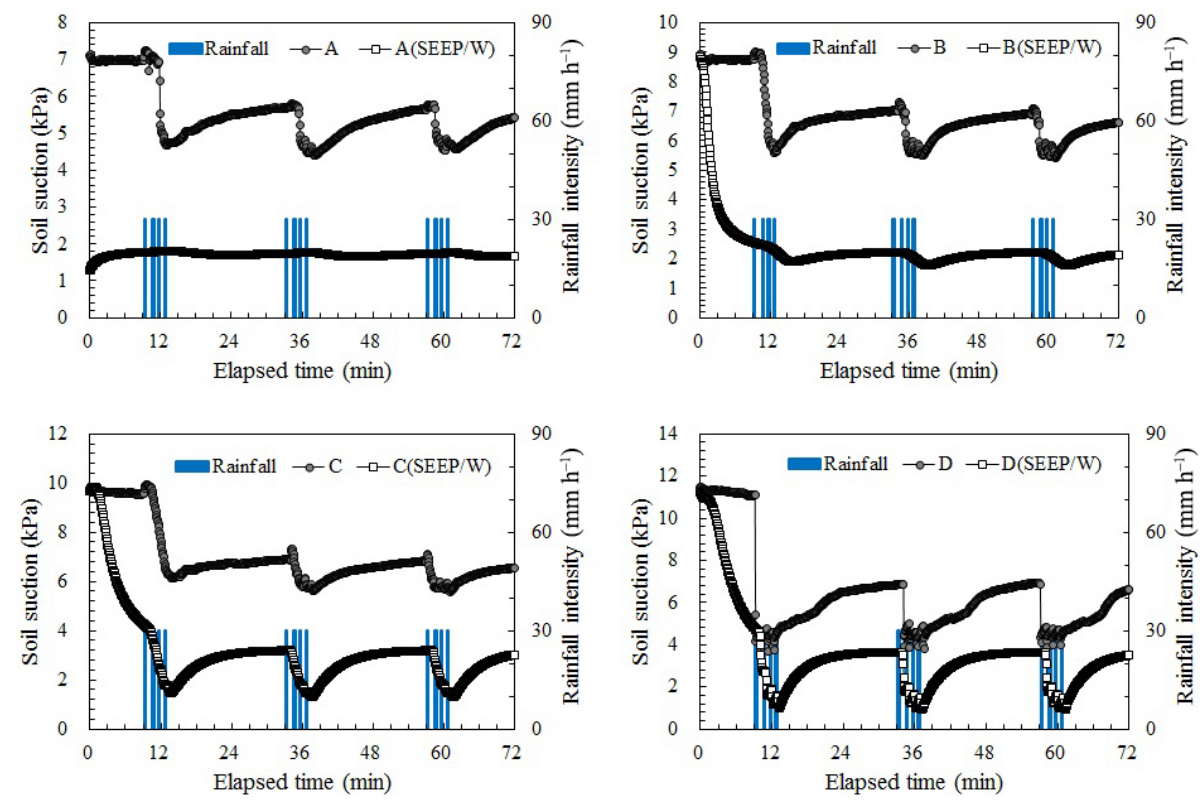

Figure 7. Comparison of soil suction of experimental data and results of numerical analysis in the model slope of $50^{\circ}$ inclination.

matric suction decreased 100 min after the rainfall simulation began. Slope failure occurred $40 \mathrm{~min}$ after the decrease in matric suction. As shown in Fig. 9a, water content increased dramatically, but the matric suction decreased slowly compared to the increase in water content (Fig. 10a). Matric suction decreased continuously until the slope failure occurred at about $5 \mathrm{kPa}$.
As seen with the water content measurement results, the failure of model slope happened when the area around the failure surface was unsaturated. In sensor B, which was placed at the center of the slope, rainfall seeped through the tensiometer cable, leading to noise appearing between 180 and 260 min of measurement (Fig. 10b). 

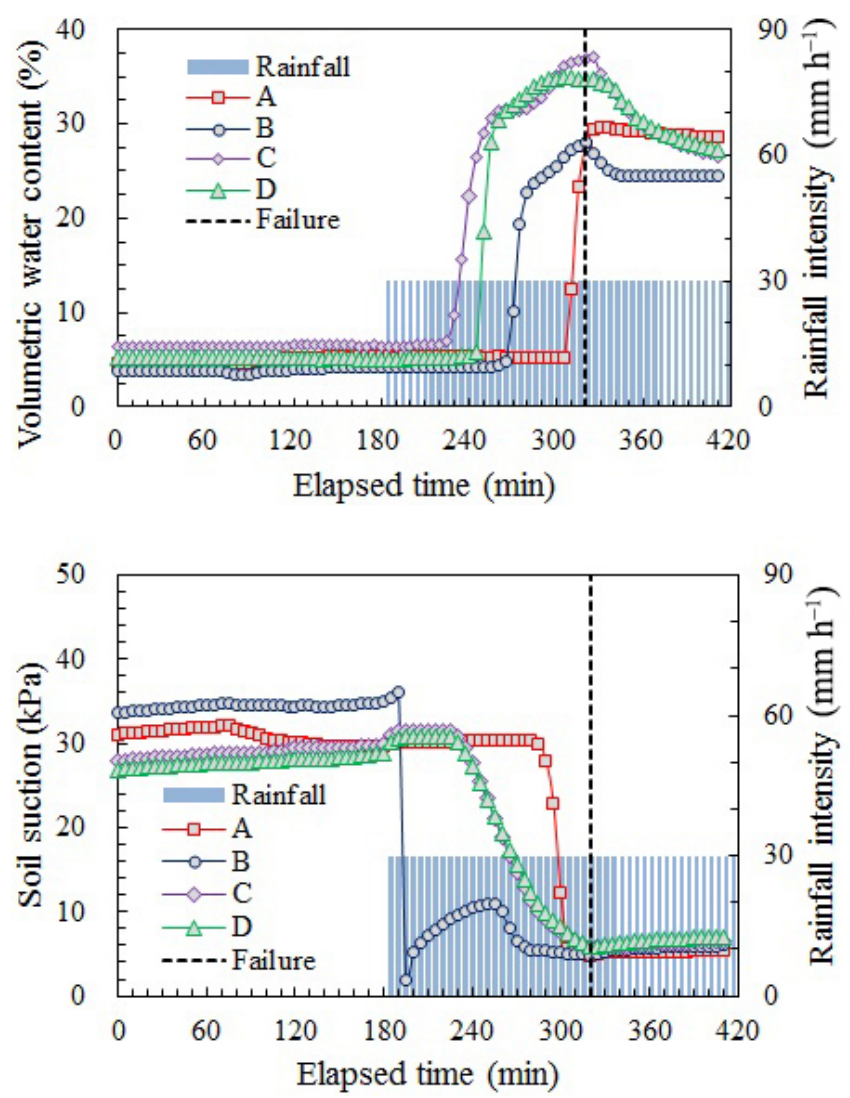

Figure 8. Variation of volumetric water content and soil suction in the model slope of $70^{\circ}$ inclination: (a) volumetric water content, (b) soil suction.

Figure 9 compares the changes in the water contents of the model slope experiment and the numerical analysis. In Fig. 9, the circles in the legend denote the experimental results, the squares denote the results of numerical analysis. Rainfall denotes the rainfall time and rainfall intensity; also failure denotes the time of slope failure. For sensor A, which was placed $50 \mathrm{~cm}$ from the top, the water content increased at the same time, but there was a difference in the amount of the increase (Fig. 9a). For the model slope experiment, slope failure occurred about $30 \mathrm{~min}$ after the water content increased at sensor A. For sensor B, which was placed $35 \mathrm{~cm}$ from the top, water content increased $50 \mathrm{~min}$ later in the numerical analysis than in the model experiment. The amount of increase also appeared to be different (Fig. 9b). For sensor $\mathrm{C}$, which was placed $20 \mathrm{~cm}$ from the top, the amount of increase in water content and the time at the start of the increase were about the same (Fig. 9c). In the numerical analysis, the seepage behaviors were the same for sensors $\mathrm{C}$ and $\mathrm{D}$, which were placed at the same depth. However, in the model slope experiment, slope failure occurred later in sensor D (Fig. 9d). In the numerical analysis, water content increased relatively gently compared to the model experiment.
For all of the sensors, the amount of increase in the water content was about the same. The early measurement of water content was $17 \%$. It increased to about $35 \%$, due to rainfall seepage, and stayed about constant until the slope failure.

Figure 10 compares the changes in matric suction in the model slope experiment and the numerical analysis. For sensor A, which was placed $50 \mathrm{~cm}$ from the top of slope, the amount of decrease and the time at the start of the decrease were about the same, which was similar to the changes in water content (Fig. 10a). For sensor B, which was placed $35 \mathrm{~cm}$ from the top, matric suction started decreasing $75 \mathrm{~min}$ later in the numerical analysis than in the model experiment (Fig. 10b). From the results of comparison of numerical analysis and the model slope experiment, it is seen that for sensor A, which was placed $50 \mathrm{~cm}$ from the top of slope, the behavior was similar. However, for sensors $\mathrm{C}$ and $\mathrm{D}$, which were placed $20 \mathrm{~cm}$ from the top of slope, matric suctions were shown in the numerical analysis to have occurred faster overall than in the experimental results.

In the numerical analysis, matric suction continuously decreased, due to rainfall seepage, until converging to $0 \mathrm{kPa}$ at $165 \mathrm{~min}$. Slope failure occurred $210 \mathrm{~min}$ after the rainfall simulation began. When matric suctions at the time of slope failure are compared, matric suction in the model slope experiment was measured to be about $5 \mathrm{kPa}$, and about $0.2 \mathrm{kPa}$ in the numerical analysis, which shows that slope failure happened at a higher matric suction in the model slope experiment.

Figure 11 shows changes in the factor of safety in the unsaturated slope stability analysis. Forty minutes after the rainfall simulation began, the factor of safety started decreasing dramatically, dropping to below 1 (slope failure) after about $130 \mathrm{~min}$. In the model slope experiment, slope failure happened $140 \mathrm{~min}$ after the rainfall simulation began. Slope failure occurred $10 \mathrm{~min}$ earlier in the unsaturated slope stability analysis.

Figure 12 compares the failure shape in the model slope experiment and in the unsaturated slope stability analysis. In the unsaturated slope stability analysis, the simulated failure surface showed a toe failure shape. In the model experiment, the slope failure showed an arc formation with multiple tensile cracks, which measured $16 \mathrm{~cm}$ parallel along the slope crown and $45 \mathrm{~cm}$ down from the crown. When the actual failure surface and the simulated failure surface were compared, both showed an arc form of failure, while the actual failure surface appeared as a smaller shape inside the slope, compared to the simulated failure surface with a toe failure shape. If the failure mass of the slope is retained by a fixed support at its toe, there may be some displacement with very slow movement in the head reach of the failure mass (Regmi et al., 2014).

The results demonstrated that the water content increased drastically due to rainfall seepage, and matric suction decreased at a slower pace than the water content. In the numerical analysis, the seepage behavior of matric suction was 

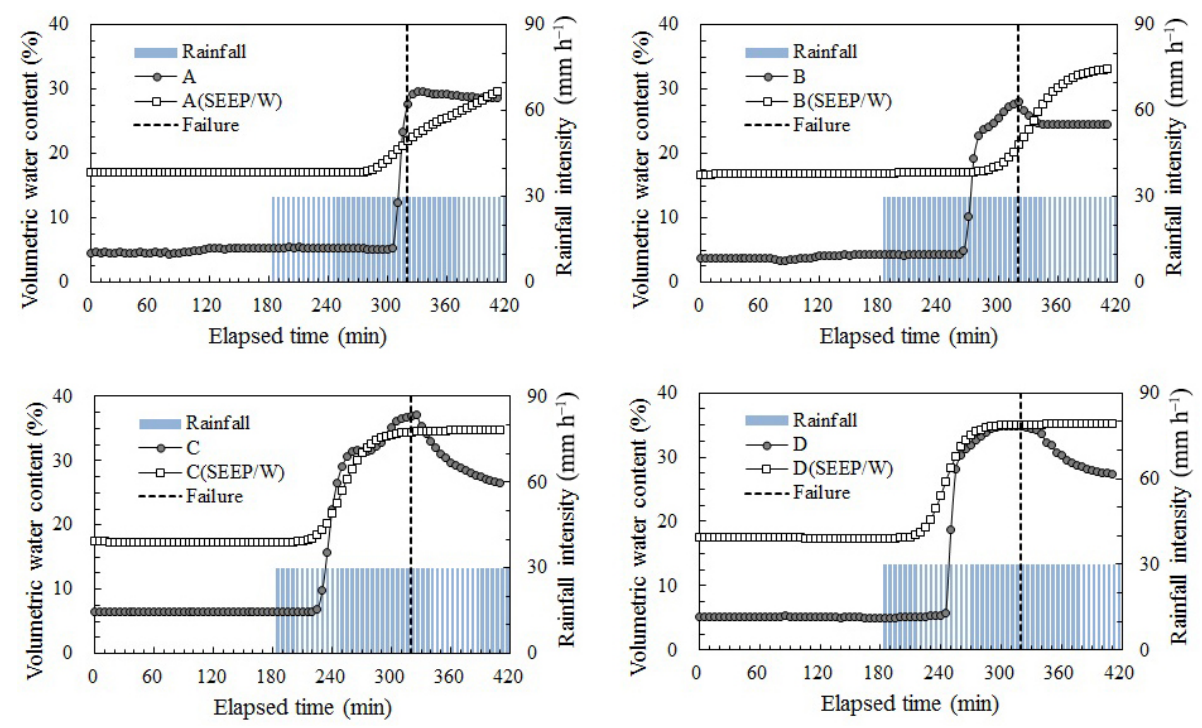

Figure 9. Comparison of volumetric water content of experimental data and results of numerical analysis in the model slope of $70^{\circ}$ inclination.
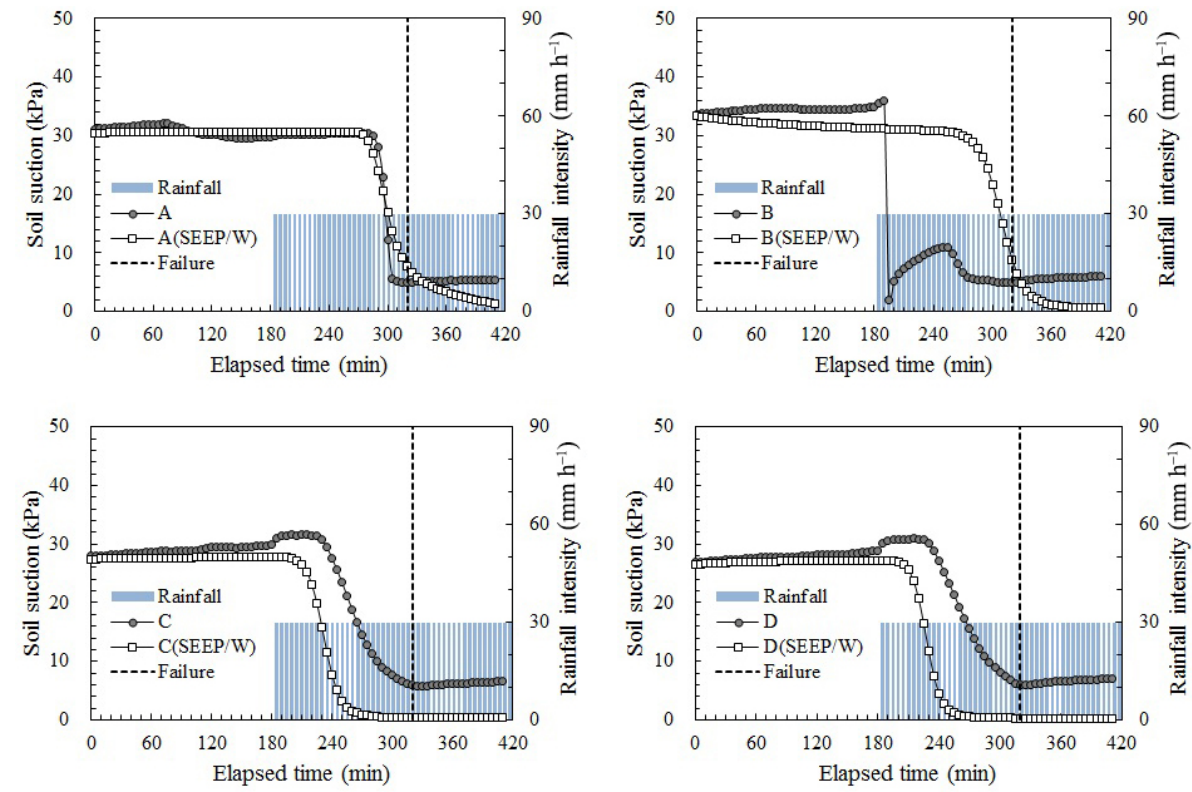

Figure 10. Comparison of soil suction of experimental data and results of numerical analysis in the model slope of $70^{\circ}$ inclination.

almost the same as in the experiment, but the amount and the rate of increase in water content due to rainfall seepage were lower than in the experiment. In the end, this acted as a factor determining the shape of failure and the differences in slope failure time. The factor of safety in an unsaturated slope is shown as a ratio of load factor and shear resistance factor, inputting the distribution of total head calculated from seepage analysis.

When the model experiment and the numerical analysis are compared, the behavior of matric suction, which acts as a shear resistance factor, was almost the same at sensors A and
B; but matric suction at sensors $\mathrm{C}$ and $\mathrm{D}$ was shown to occur rapidly in the numerical analysis. As a consequence, slope failure occurred more quickly in the numerical analysis than in the model experiment.

\section{Conclusion}

In this study, we performed a model slope experiment with rainfall seepage, and the results were compared and verified using the unsaturated slope stability analysis method. In the 


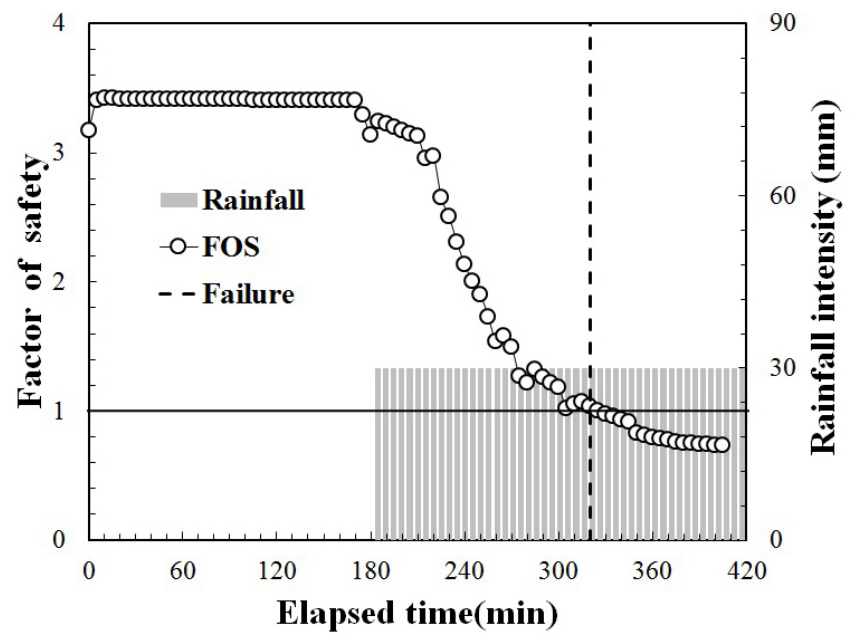

Figure 11. Factor of safety with time.

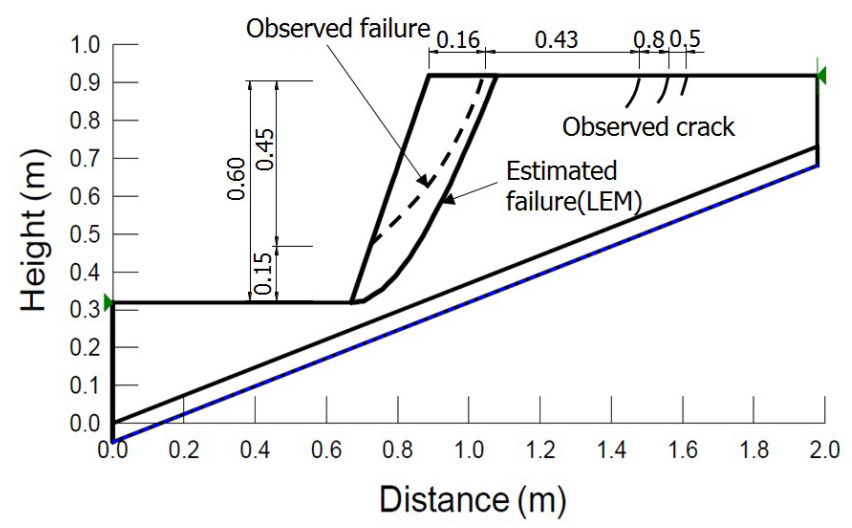

Figure 12. Comparison of failure shape.

model slope experiment, we measured the changes in water content and matric suction due to rainfall seepage, and determined the time at which the slope failure occurred and the shape of the failure. In addition, we compared and verified the changes in the factor of safety and the shape of the failure surface, which was calculated from the unsaturated slope stability analysis with the model experiment.

The conclusions from this study are as follows.

1. From the results of numerical analysis and the model slope experiment of $50^{\circ}$ inclination, an increase of water contents and a decrease of matric suctions due to rainfall seepage occurred rapidly in large amounts but a decrease of water contents and an increase of matric suctions due to drainage occurred gradually in small values. This evidences a hysteresis of seepage drainage procedures in unsaturated soils. Even with similar behaviors in the model slope experiment and the numerical analysis, the difference could be considered by applying the SWRCs obtained from disturbed specimens in the numerical analysis.
2. In the model slope experiment, rainfall seepage caused the water content to increase dramatically and matric suction to decrease more gradually than water content, leading to the area around the failure surface collapsing at around $5 \mathrm{kPa}$. Model slope failure occurred when the bottom of the failure surface was unsaturated.

3. In seepage analysis, compared to the model experiment, water content increased relatively gradually, and seepage behaviors were about the same across all the sensors. Early water content was analyzed to be $17 \%$, which is higher than the results from the experiment. It increased due to rainfall seepage until it reached $35 \%$ and remained constant until slope failure. For matric suction, seepage behaviors were about the same as the experimental results, in terms of the time of matric suction decrease and the amount of the decrease.

4. Slope failure began 140 and $130 \mathrm{~min}$ after rainfall simulation began in the model slope experiment and the unsaturated slope stability analysis, respectively. In the numerical analysis, the failure started 10 min earlier. The shape of failure in the model experiment is described as showing an arc formation with multiple tensile cracks, which measured $16 \mathrm{~cm}$ parallel along the slope crown and $45 \mathrm{~cm}$ down from the crown. In the unsaturated slope stability analysis, the simulated failure surface showed a toe failure shape. When the actual failure surface and the simulated failure surface are compared, both showed an arc form of failure, while the actual failure surface appeared as a smaller shape inside the slope, compared to the simulated failure surface with a toe failure shape.

5. The results of the experiment showed that water content increased dramatically due to rainfall seepage, and matric suction decreased more gradually than the water content. In the numerical analysis, the seepage behavior of matric suction was almost the same as in the experiment; but the amount and the rate of increase in water content due to rainfall seepage were lower than in the experiment. In the end, this acted as a factor determining the shape of failure and the differences in slope failure time.

From the results of the experiment and the analysis, it is concluded that unsaturated slope stability analysis can be used to accurately analyze and predict rainfall-induced slope failure. In seepage analysis, setting the initial conditions and boundary conditions is very important. If engineers will use the measured porewater pressure or matric suction, the accuracy of analysis can be enhanced. The real-time monitoring system of porewater pressure or matric suction can be used as a warning of rainfall-induced slope failure. 
Acknowledgements. This research was supported by a grant (15SCIP-B065985-03) from the Smart Civil Infrastructure Research Program funded by the Ministry of Land, Infrastructure and Transport (MOLIT) of the Korean government, and Korea Agency for Infrastructure Technology Advancement (KAIA).

Edited by: O. Katz

Reviewed by: four anonymous referees

\section{References}

Anderson, S. A. and Sitar, N.: Analysis of rainfall-induced debris flows, J. Geotech. Eng.-ASCE, 121, 544-552, 1995.

Bogena, H., Huisman, J., Oberdörster, C., and Vereecken, H.: Evaluation of a low-cost soil water content sensor for wireless network applications, J. Hydrol., 344, 32-42, 2007.

Brand, E.: Some thoughts on rain-induced slope failures, in: Proceedings of the 10th International Conference on Soil Mechanics and Foundation Engineering, Stockholm, 15-19, 1981.

Brenner, R., Tam, H., and Brand, E.: Field stress path simulation of rain-induced slope failure, in: Proceedings of 11th International Conference on Soil Mechanics and Foundation Engineering, San Francisco, 991-996, 1985.

Decagon devices: ECH2O Soil Moisture Sensor: Operators Manual for Models EC-20, EC-10 and EC-5 (Version 5), Decagon Devices Inc., Pullman, Wash., 1-20, 2006.

Fukuzono, T.: Experimental study of slope failure caused by heavy rainfall, erosion and sedimentation in the Pacific Rim, in: Proceedings of the Corvallis Symposium, August 1987, Corvallis, 1987.

Indrawan, I. G. B., Rahardjo, H., Leong, E. C., Tan, P. Y., Fong, Y. K., and Sim, E. K.: Field instrumentation for monitoring of water, heat, and gas transfers through unsaturated soils, Eng. Geol., 151, 24-36, 2012.

Johnson, K. and Sitar, N.: Hydrologic conditions leading to debrisflow initiation, Can. Geotech. J., 27, 789-801, 1990.

Kitamura, R., Jomoto, K., Yamamoto, K., Terachi, T., Abe, H., and Iryo, T.: Field measurement of suction in soil and rainfall in Kagoshima Prefecture, in: Proceedings, 1st International Symposium on Slope Stability Engineering, Shikoku, 1999.

Krahn, J.: Seepage Modeling with SEEP/W 2007: an Engineering Methodology, Geo-slope International Ltd. Printed, Alberta, 1$188,2007$.

Oh, S. and Lu, N.: Slope stability analysis under unsaturated conditions: case studies of rainfall induced failure of cut slopes, Eng. Geol., 184, 96-103, 2015.
Rahardjo, H., Lee, T. T., Leong, E. C., and Rezaur, R. B.: Response of a residual soil slope to rainfall, Can. Geotech. J., 42, 340-351, 2005.

Regmi, R. K., Jung, K., Nakagawa, H., and Kang, J.: Study on mechanism of retrogressive slope failure using artificial rainfall, Catena, 122, 27-41, 2014.

Sasahara, K.: Mechanical model for prediction of steep sandy slope failure due to rainfall using surface displacement, Tsuchi-toKiso, 49, 13-15, 2001.

Sidle, R. and Swanston, D.: Analysis of a small debris slide in coastal Alaska, Can. Geotech. J., 30, 167-174, 1982.

Sitar, N., Anderson, S. A., and Johnson, K. A.: Conditions for initiation of rainfall-induced debris flows, Stability and performance of slopes and embankments II, Geotechnical Special Publication (GSP) No. 31, ASCE, 834-849, 1993.

Tami, D., Rahardjo, H., and Leong, E. C.: Effects of hysteresis on steady-state infiltration in unsaturated slopes, J. Geotech. Geoenviron., 130, 956-967, 2004.

Tohari, A., Nishigaki, M., and Komatsu, M.: Laboratory rainfallinduced slope failure with moisture content measurement, J. Geotech. Geoenviron., 133, 575-587, 2007.

Topp, G., Davis, J., and Annan, A. P.: Electromagnetic determination of soil water content: measurements in coaxial transmission lines, Water Resour. Res., 16, 574-582, 1980.

Van Genuchten, M. T.: A closed-form equation for predicting the hydraulic conductivity of unsaturated soils, Soil Sci. Soc. Am. J., 44, 892-898, 1980.

Wang, G. and Sassa, K.: Pore-pressure generation and movement of rainfall-induced landslides: effects of grain size and fine-particle content, Eng. Geol., 69, 109-125, 2003.

Wieczorek, G. F.: Landslide triggering mechanisms, in: Landslide: Investigation and mitigation (Special Report), edited by: Turner, A. K. and Schuster, R. L., Special Report 247, National Research Council, Transportation and Research Board, Washington, D.C., 76-90, 1996.

Yagi, N. and Yatabe, R.: Prediction method of slope failure in sandy soil due to rainfall, in: Proceedings, 8th Asian Regional Conference on Soil Mechanics and Foundation Engineering, Kyoto, 1987.

Yokota, S., Iwamatsu, A., Imura, R., Matsuyuki, K., and Ohkawa, T.: A new warning index for debris flows based on rainfall and groundwater depth, in: Proceedings, GeoEng2000: an International Conference on Geotechnical and Geological Engineering, Melbourne, 2000. 